\title{
Perancangan dan Implementasi Aplikasi TOEFL pada Perangkat Android
}

\author{
Yolen Perdana Sari ${ }^{1}$ \\ ${ }^{1}$ Teknik Informatika, Universitas Pamulang \\ J1. Surya kencana no 1, Pamulang, Tangerang Selatan \\ e-mail: 1dosen01705@unpam.ac.id
}

\begin{abstract}
Mobile phone and its applications is growing rapidly after this millennium era. It seems not difficult to imagine that in the future we will bring a device other than as a technology in which the mobile communication device, is also capable of playing music and video DVDs, watch TV, play games, digital cameras, read books, guide maps, banking transaction, browsing, and so forth. One application of technology that is a trend today is the development of mobile application for Android devices. An open platform is provided by android so the application can made by developers.

Mobile application that made in this Final Project is the application of the Test of English as a Foreign Language. TOEFL recommendation has been through in almost every educational institution, so there is some application that utilized TOEFL as a training tool that can improve their TOEFL score. Along with technological development in the modern era who want a service that is not limited by place and time, practice TOEFL can be made on mobile devices more flexible and efficient. Therefore constructed a TOEFL application using the Android operating system.

The results of tests performed showed that these applications can run all the functions and features are as expected. Then the application is very helpful for the user in preparing their Toefl test.
\end{abstract}

Keyword : Mobile application, Android, Test of English as a Foreign Language.

\section{Pendahuluan}

TOEFL adalah kepanjangan dari Test of English as a Foreign Language. TOEFL dibuat oleh ETS yang merupakan lembaga bahasa yang berada di Amerika Serikat. TOEFL digunakan untuk memberikan penilaian secara umum terhadap kemampuan peserta dalam membaca, menulis dan mendengarkan bahasa inggris. Kebutuhan akan rekomendasi nilai TOEFL telah menyeluruh hampir di setiap institusi pendidikan, termasuk institusi pendidikan di dalam negri. Hal ini yang menyebabkan munculmya beberapa aplikasi TOEFL yang dimanfaatkan sebagai sarana latihan bagi para user untuk meningkatkan nilai TOEFL mereka.

Seiring dengan kebutuhan dan permintaan user yang menginginkan layanan yang tidak terbatas oleh jarak dan ruang, latihan TOEFL ini dibuat pada perangkat mobile yang sifatnya lebih fleksibel. Oleh karena itu dibangun suatu aplikasi Toefl pada perangkat yang menggunakan operating system
Android. Android merupakan OS yang digemari oleh banyak mobile phone saat ini karena bersifat open source sehingga developer bisa mengkonfigurasi fitur sesuai dengan kebutuhan. Selain itu, mobile phone pendukung OS Android mulai berkembang dengan kualitas dan harga yang variatif yang dapat dijangkau oleh kalangan muda, tua ataupun para pelajar dari berbagai kalangan umur.

\section{Dasar Teori}

\subsection{Test of English as Foreign Language}

TOEFL terbagi menjadi 3 jenis, computer based test disingkat CBT, internet based test disingkat iBT, dan paper based test disingkat PBT. Berdasarkan namanya, CBT dan iBT menggunakan media komputer sedangkan PBT menggunakan kertas. Pada PBT soal terbagi menjadi 4 bagian: Listening, Structure and Written Expression, Reading Comprehension, dan Writing. (putra, suryono, \& darmini, 2009) 
Ujian TOEFL yang paling sering dipakai di Indonesia adalah ITP atau Institutional Testing Program. ITP adalah TOEFL yang setipe PBT dengan tes terdiri dari 3 bagian, Listening, Structure and Written Expression, dan Reading dengan range penilaian total untuk ketiga bagian soal adalah $310-677$.

\subsubsection{Listening Comprehension}

Listening Comprehension adalah bagian awal dari tes TOEFL. Listening Comprehension terdiri dari 50 soal dengan waktu 30-40 menit, peserta ujian diberikan kesempatan untuk mendengarkan artikel dan soal yang biasanya dibacakan oleh native speaker.

\subsubsection{Structure and Written Expression}

Pada bagian structure and written expression terdapat 40 soal mengenai tata bahasa Inggris. Soal dibagi menjadi 2 bagian, structure dan soal mengenai written expression. Dalam waktu 25 menit peserta ujian diminta untuk menentukan kesalahan pada kalimat soal dalam bahasa Inggris.

\subsubsection{Reading Comprehension}

Pada bagian reading comprehension tersedia waktu 45 menit untuk mengerjakan 50 soal. Setiap pertanyaan diawali dengan artikel yang harus dibaca dan dipahami peserta ujian dengan cepat.

Cara menghitung skor TOEFL keseluruhan

1. Jumlahkan skor hasil konversi dari jumlah jawaban benar dari tabel

Jumlah $=$ skor listening + skor writing + skor reading

2. Cari rata rata nilainya dengan membagi 3 jumlah yang didapat dari langkah 1 Hasil bagi $=$ Jumlah : 3

3. Hasil TOEFL didapat hasil bagi dikali 10 nilai $\mathrm{TOEFL}=10 \times$ Hasil bagi

Hasil TOEFL didapat berdasarkan jumlah jawaban yang benar dari tiap bagian. Hasil skor TOEFL dapat dijelaskan sesuai table konversi di bawah:
Tabel 1: Penilaian TOEFL

\begin{tabular}{|c|c|c|c|}
\hline $\begin{array}{l}\text { jumlah } \\
\text { benar }\end{array}$ & $\begin{array}{c}\text { konversi skor } \\
\text { resi } 1\end{array}$ & $\begin{array}{c}\text { komversi skor } \\
\text { sesi } 2\end{array}$ & $\begin{array}{c}\text { komversi skor } \\
\text { sesi } 3\end{array}$ \\
\hline 50 & 68 & - & 67 \\
\hline 49 & 67 & - & 66 \\
\hline 48 & 66 & - & 65 \\
\hline 47 & 65 & - & 63 \\
\hline 46 & 63 & - & 61 \\
\hline 45 & 62 & - & 60 \\
\hline 44 & 61 & - & 59 \\
\hline 43 & 60 & - & 58 \\
\hline 42 & 59 & - & 57 \\
\hline 41 & 58 & - & 56 \\
\hline 40 & 57 & 68 & 55 \\
\hline 39 & 57 & 67 & 54 \\
\hline 38 & 56 & 65 & 54 \\
\hline 37 & 55 & 63 & 53 \\
\hline 36 & 54 & 61 & 52 \\
\hline 35 & 54 & 60 & 52 \\
\hline 34 & 53 & 58 & 51 \\
\hline 33 & 52 & 57 & 50 \\
\hline 32 & 52 & 56 & 49 \\
\hline 31 & 51 & 55 & 48 \\
\hline 30 & 51 & 54 & 48 \\
\hline 29 & 50 & 53 & 47 \\
\hline 28 & 49 & 52 & 46 \\
\hline 27 & 49 & 51 & 46 \\
\hline 26 & 48 & 50 & 45 \\
\hline 25 & 48 & 49 & 44 \\
\hline 24 & 47 & 48 & 43 \\
\hline 23 & 47 & 47 & 43 \\
\hline 22 & 46 & 46 & 42 \\
\hline 21 & 45 & 45 & 41 \\
\hline 20 & 45 & 44 & 40 \\
\hline 19 & 44 & 43 & 39 \\
\hline 18 & 43 & 43 & 38 \\
\hline 17 & 42 & 41 & 37 \\
\hline 16 & 41 & 40 & 36 \\
\hline 15 & 41 & 40 & 35 \\
\hline 14 & 39 & 38 & 34 \\
\hline 13 & 38 & 37 & 32 \\
\hline 12 & 37 & 36 & 31 \\
\hline 11 & 35 & 35 & 30 \\
\hline 10 & 33 & 33 & 29 \\
\hline 9 & 32 & 31 & 28 \\
\hline 8 & 32 & 29 & 28 \\
\hline 7 & 31 & 27 & 27 \\
\hline 6 & 30 & 26 & 26 \\
\hline 5 & 29 & 25 & 25 \\
\hline 4 & 28 & 23 & 24 \\
\hline 3 & 27 & 22 & 23 \\
\hline 2 & 26 & 21 & 23 \\
\hline 1 & 25 & 20 & 22 \\
\hline 0 & 24 & 20 & 21 \\
\hline
\end{tabular}

\subsection{Aplikasi Bergerak (Mobile Aplication)}

Aplikasi bergerak atau yang biasa disebut dengan mobile application adalah suatu aplikasi yang dipakai pada perangkat elektronik bergerak, smartphone atau komputer tablet

Aplikasi bergerak terdiri dari beberapa jenis yaitu:

a. Native App: Aplikasi bergerak yang dikembangkan hanya untuk perangkat tertentu, seperti android yang dibuat dengan java dan aplikasi IOS yang dibuat dengan objective-C. 
b. Web App: Aplikasi yag dapat dijalankan pada browser seperti crome atau firefox

c. Hybrid App: Prinsip dari native app dan web app yang digabungkan

\subsection{Android}

\subsubsection{Pengertian Android}

Android merupakan suatu Operating System yang menyediakan platform terbuka. Dengan platform terbuka developer bisa membuat aplikasi sendiri dengan menggunakan bahasa pemograman Java untuk android. (Roger \& dkk, 2009) Android dikembangkan oleh Open Handset Alliance yang merupakan kumpulan dari 34 perusahaan software, hardware, dan telecommunication.

\subsubsection{Arsitektur Android}

Android memiliki arsitektur sistem yang kompleks seperti berikut:

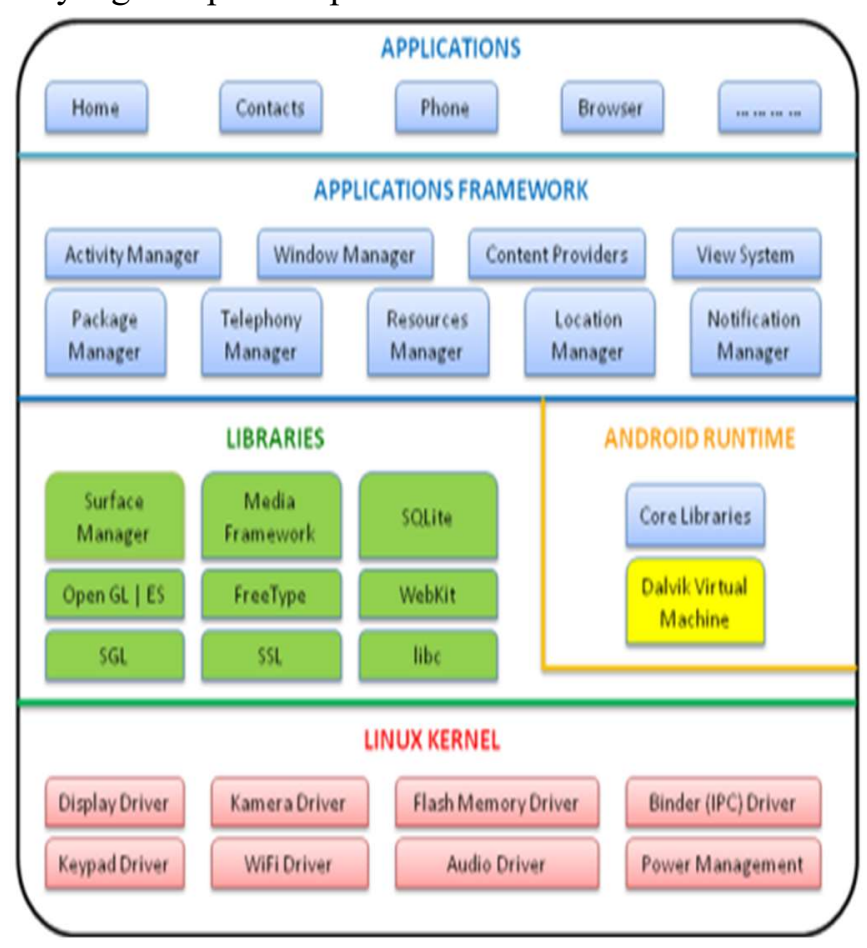

Gambar 1: Arsitektur android (Murphi, Beginning Android, 2009)

\subsubsection{Software Development Kit}

Software development kit atau yang bisa disingkat android SDK adalah perangkat API tempat aplikasi dikembangkan pada android. Android SDK memakai bahasa pemrograman Java untuk android. (Murphi,
Android Programming Tutorial, 2009) Libraries, debugger, dokumentasi, handset emulator, kode, tutorial adalah komponen komponen yang terdapat pada android SDK

\subsubsection{Android Development Tools}

Android Development Tools adalah suatu alat untuk membuat dan mengembangkan aplikasi android. ADT biasa disebut plugins eclipse, ADT diinstall agar IDE Eclipse terhubung dengan Android SDK yang sudah ada.

\section{Perancangan dan Implementasi}

\subsection{Rancangan Sistem}

Sistem yang akan dikembangkan terdiri 4 bagian yaitu, perangkat bergerak dengan OS android, database lokal dari perangkat tersebut yang dapat diakses langsung ketika membuka aplikasi tanpa memerlukan jaringan internet, server berupa notebook atau PC, database yang tersimpan di server yang dapat diakses sewaktu waktu ketika adanya permintaan dari perangkat android yang terhubung ke jaringan internet.

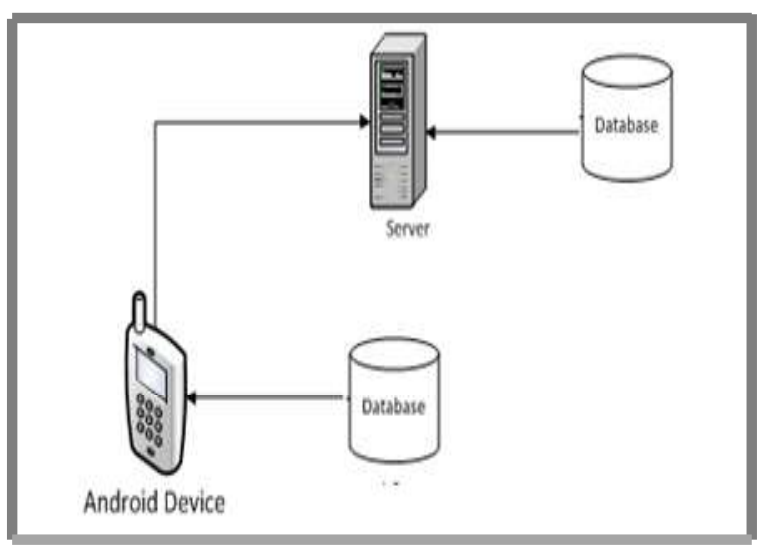

Gambar 2: Gambaran umum sistem

\subsection{Analisis}

\subsubsection{Gambaran Kebutuhan}

Beberapa aspek pendukung yang dibutuhkan dalam pengembangan aplikasi TOEFL ini adalah sebagai berikut:

1. Software

Software atau perangkat lunak yang dipakai adalah Android Software Development Kit, Development Kit Java SE, IDE Eclipse, SQLite 
Database, Microsoft Visio 2007, Android Development Tools (ADT)

\section{Hardware}

Hardware atau perangkat keras yang digunakan memiliki spesifikasi Prosessor Intel $\AA$ Core 2 Duo CPU T5670, Hard Disk 80 GB, RAM 2 GB, Perangkat masukan mouse, Perangkat keluaran monitor komputer

3. Pengguna (User)

Pengguna aplikasi TOEFL secara umum sudah mahir memakai perangkat bergerak android, mengenal aplikasi yang dioperasikan pada android, serta sudah terbiasa sebelumnya menggunakan aplikasi yang dioperasikan pada android.

\subsubsection{Analisis Pengguna}

Menu menu pada aplikasi TOEFL ini dapat diakses oleh pengguna ketika membuka aplikasi TOEFL. Dengan adanya menu menu tersebut maka pengguna dapat:
a. Melatih kemampuan bahasa Inggris
b. Melatih kemampuan TOEFL
c. Melihat hasil score TOEFL user
d. Menambah kemampuan bahasa Inggris user

\subsection{Perancangan}

\subsubsection{Perancangan Sistem}

Perancangan aplikasi TOEFL ini menggunakan Unified Model Languange (UML). Fungsi UML pada implementasi aplikasi ini hanya terbatas pada activity diagram dan use case diagram. Penjelasan dari activity diagram dan use case diagram sebagai berikut:

\section{Use case Diagram}

Use case diagram menunjukan kegunaan dari masing masing menu pada aplikasi TOEFL. Pada aplikasi ini use case diagram secara umum ditunjukan dengan gambar di bawah ini:

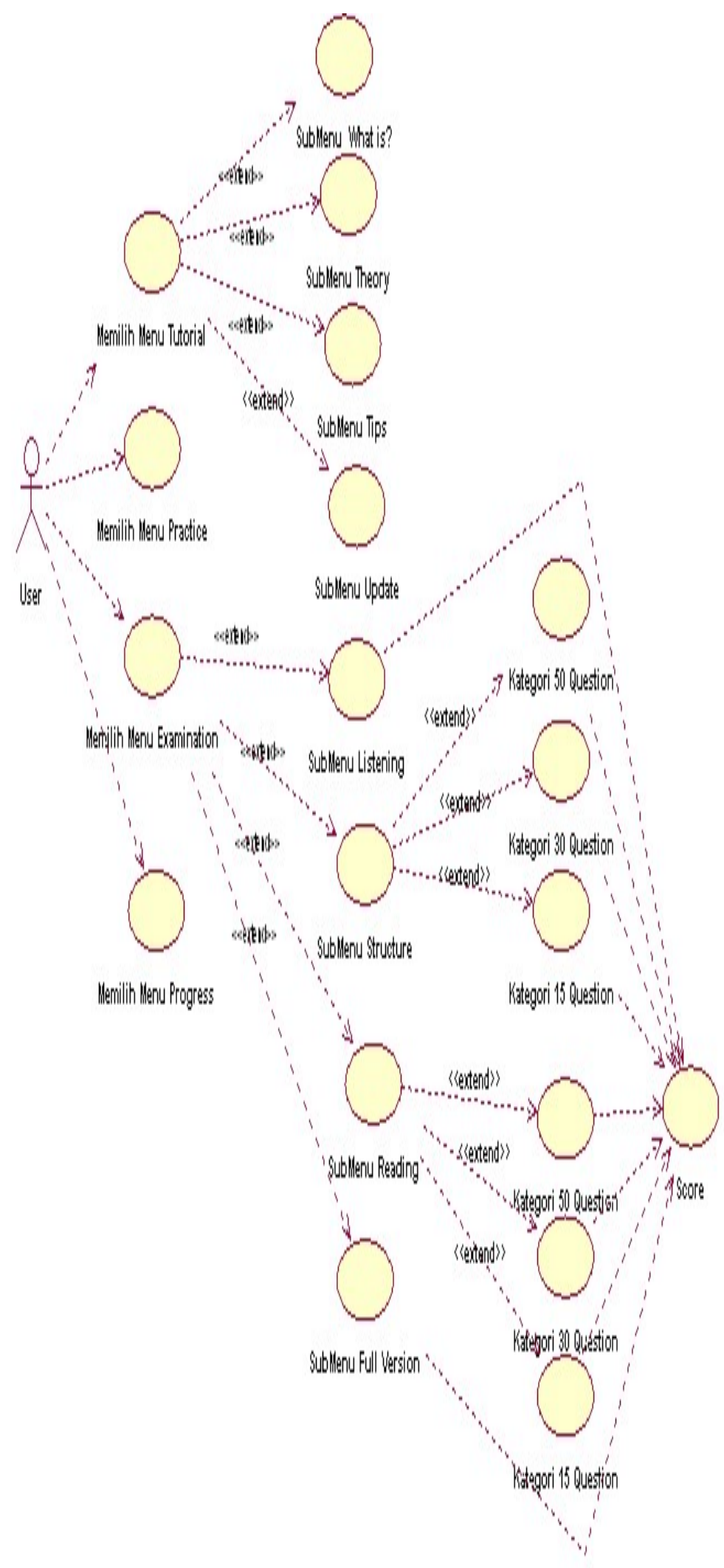

Gambar 3 : Use Case Diagram Menu Utama 


\section{Activity Diagram}

Activity diagram menunjukan aktivitas yang dilakukan oleh user pada aplikasi dan bagaimana respon yang diharapkan dari sistem aplikasi. Pada perancangan aplikasi TOEFL dijelaskan dengan gambar berikut:

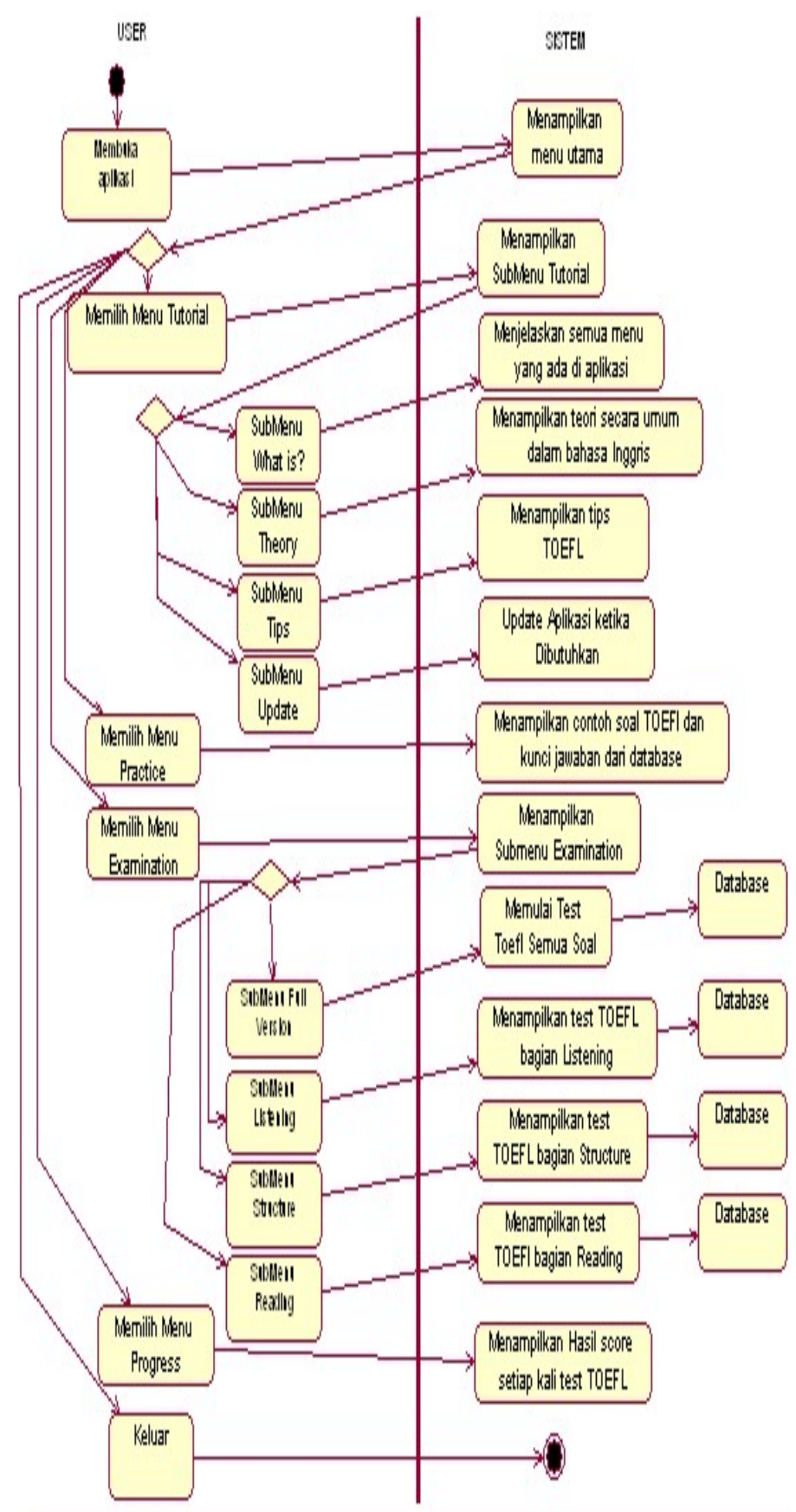

Gambar 4 : Activity Diagram

\section{Uji Aplikasi dan Analisis}

\subsection{Uji Aplikasi}

Pada aplikasi TOEFL ini dilaksanakan dua pengujian, yaitu pengujian fungsional dan pengujian performansi berdasar hasil quisioner dari para responden.

Pengujian aplikasi ini menggunakan metode pengujian blackbox yang menitikberatkan pada fungsi aplikasi TOEFL yang sudah diimplementasikan. Pengujian sistem aplikasi TOEFL bisa digambarkan dengan tabel di bawah ini:

Tabel 2: Pengujian sistem

\begin{tabular}{|c|c|c|}
\hline Kelas Uji & Butir Uji & $\begin{array}{l}\text { Jenis } \\
\text { Pengujian }\end{array}$ \\
\hline $\begin{array}{l}\text { Menu } \\
\text { Utama }\end{array}$ & $\begin{array}{l}\text { Menampilkan } \\
\text { Menu Utama }\end{array}$ & Black Box \\
\hline \multirow{4}{*}{ Tutorial } & \begin{tabular}{ll}
\multicolumn{2}{l}{ Menampilkan } \\
penjelasan & dari \\
tiap menu yang \\
ada & pada \\
Aplikasi &
\end{tabular} & Black Box \\
\hline & $\begin{array}{l}\text { Menampilkan } \\
\text { teori dasar untuk } \\
\text { persiapan test } \\
\text { TOEFL } \\
\end{array}$ & Black Box \\
\hline & $\begin{array}{l}\text { Menampilkan } \\
\text { tips dan trik test } \\
\text { TOEFL }\end{array}$ & Black Box \\
\hline & $\begin{array}{l}\text { Menampilkan } \\
\text { sub-menu } \\
\text { Update aplikasi }\end{array}$ & Black Box \\
\hline Practice & $\begin{array}{l}\text { Menampilkan } \\
\text { contoh soal dan } \\
\text { jawaban }\end{array}$ & Black Box \\
\hline \multirow{4}{*}{ Examination } & $\begin{array}{l}\text { Menampilkan } \\
\text { test TOEFL } \\
\text { bagian listening }\end{array}$ & Black Box \\
\hline & $\begin{array}{l}\text { Menampilkan } \\
\text { test TOEFL } \\
\text { bagian structure }\end{array}$ & Black Box \\
\hline & $\begin{array}{l}\text { Menampilkan } \\
\text { test Toefl bagian } \\
\text { reading }\end{array}$ & Black Box \\
\hline & $\begin{array}{l}\text { Menampilkan } \\
\text { test TOEFL } \\
\text { secara } \\
\text { keseluruhan }\end{array}$ & Black Box \\
\hline
\end{tabular}




\subsubsection{PengujianAlpha}

Pengujian alpha merupakan pengujian pada hasil keluaran dari masukan yang dilakukan pada form tampilan. Pengujian dikatakan berhasil apabila output sesuai dengan input. Pengujian alpha terdiri dari membuka aplikasi TOEFL pada perangkat, Menu Utama pada aplikasi, Menu "Tutorial" beserta submenu di dalamnya, Menu "Practice' beserta submenu di dalamnya, Menu "Examination" beserta submenu di dalamnya, dan Menu "Progress"

\subsubsection{Pengujian Beta}

Pengujian beta adalah pengujian yang dilakukan secara langsung kepada para pengguna, aplikasi ini diujikan kepada beberapa orang mahasiswa IT Telkom yang menggunakan beberapa jenis mobile device Android dengan total responden berjumlah dua puluh (20) orang. Kemudian dilakukan perhitungan untuk mengambil kesimpulannya terhadap penilaian dari aplikasi dari lembar kuiioner yang sudah dilampirkan.

tPerhitungan prosentase jawaban menggunakan: $\mathrm{X}=\mathrm{A} / \mathrm{B} * 100 \%$

Keterangan:

$A=$ Jumlah jawaban responden tiap soal

$\mathrm{B}=$ Jumlah responden

$\mathrm{X}=$ Nilai Prosentase

\subsection{Analisis Implementasi}

Dari hasil perancangan dan implementasi system aplikasi TOEFL pada android maka didapat beberapa analisis implemengtasi sebagai berikut:

1. Pada tahap perancangan Tugas Akhir ini, sistem TOEFL yang dirancang disesuaikan dengan TOEFL yang sebenarnya yang terdiri dari 140 soal dengan waktu pengerjaan selama 120 menit. Tapi ketika tahap implementasi, selain soal full, juga dibuat sistem pilihan jenis soal dan jumlah soal yang akan diujikan. Hal ini dapat dilihat pada grafik 4.6 tentang Pengujian fungsi menu jenis soal dan jumlah soal pada aplikasi dimana sebanyak $75 \%$ responden menyatakan menu tersebut membantu user dalam mempersiapkan test TOEFL, sedangkan $25 \% \quad$ responden menyatakan sangat membantu.

2. Pada tahap implementasi aplikasi ini hanya dibuat 1 tipe soal berjumlah 140 soal, 50 soal listening, 40 soal structure, dan 50 soal reading. Sesuai dengan grafik 4.6 tentang soal-soal yang ada, $55 \%$ responden menjawab soal pada aplikasi ini cukup banyak, sedangkan $35 \% \quad$ responden menjawab kurang banyak. Oleh Karena itu, untuk menanggulangi keterbatasan jumlah soal, maka ditambahkan sub-menu "update aplikasi” pada aplikasi ini, sehingga soal-soal yang ada dapat di replace dan user bisa menggunakan soal yang berbeda.

\section{KESIMPULAN DAN SARAN}

\subsection{Kesimpulan}

Dari keseluruhan perancangan, implementasi, pengujian, serta analisis sistem pada aplikasi TOEFL dapat diperoleh kesimpulan sebagai berikut:

1. Aplikasi TOEFL ini sudah dapat langsung digunakan oleh user setelah aplikasi terpasang pada mobile device.

2. Berdasarkan pengujian alpha diperoleh kesimpulan bahwa semua menu dalam aplikasi ini sudah berjalan dengan baik dan dapat diterima sesuai dengan skenario rencana pengujian.

3. Berdasarkan tingkat kebutuhan penggunaannya, aplikasi ini dibutuhkan oleh user dalam persiapan menghadapi ujian TOEFL. Hal ini berdasarkan hasil pengujian betha dengan $70 \%$ responden menjawab aplikasi ini sangat membantu dalam persiapan menghadapi ujian TOEFL

4. Penilaian fungsi aplikasi secara umum $85 \%$ responden menjawab baik, tampilan interface $85 \%$ responden menjawab bagus, dan kesesuaian aplikasi dengan tes TOEFL yang sebenarnya $70 \%$ responden menjawab sesuai/ sudah merepresentasikan. 


\subsection{Saran}

Beberapa saran untuk pengembangan aplikasi TOEFL pada android:

1. Penambahan jumlah tipe soal pada aplikasi, sehingga jumlah soal yang diujikan lebih banyak, bahkan ada pilihan jenis TOEFL apa yang akan dipakai yaitu iBT, CBT, atau PBT.

2. Dibangun aplikasi TOEFL secara online

\section{DAFTAR PUSTAKA}

[1] Allen, G. (2009). The Definite Guided to SQLiite. New York: Apress.

[2] Meier, R. (2009). Profesional Android Application Development. Indianapolis: Wrox.

[3] Murphi, M. (2009). Android Programming Tutorial. New York: Apress.

[4] Murphi, M. (2009). Beginning Android. New York : Apress.

[5] putra, a. d., suryono, r. r., \& darmini, d. (2009, juni 20). Rancang Bangun Media Pembelajaran TOEFL berbasis Web. Seminar Nasional Aplikasi Teknologi Informasi .

[6] Roger, R., \& dkk. (2009). Android Application Development. Sebatopol: O'Reilly.

[7] Safaat, N. (2011). Pemograman Aplikasi Mobile Smartphone dan tablet PC berbasis android. Bandung: Informatika. 